\title{
Effect of concept mapping on problem solving skills, competence in clinical setting and knowledge among undergraduate nursing students
}

\author{
Seham A. Abd El-Hay;, Samira E. El Mezayen, Rasha E. Ahmed \\ Faculty of Nursing, Tanta University, Tanta, Egypt
}

Received: January 30, 2018

Accepted: March 19, 2018

Online Published: March 25, 2018

DOI: $10.5430 /$ jnep.v8n8p34

URL: https://doi.org/10.5430/jnep.v8n8p34

\begin{abstract}
Background and objective: Concept mapping is a powerful instructional tool in the clinical settings that improves competency of undergraduate nursing students in interprets situations, problem solving, decision making and critical thinking in different circumstances. Also enable them to provide optimal comprehensive care for clients. This study was conducted to evaluate the effect of concept mapping on problem solving skills, competence in the clinical settings and knowledge among undergraduate nursing students.

Methods: Design and Setting: A quasi-experimental design was used and data were collected from Medical \& Surgical Nursing Department and Community Health Nursing Department labs in the Faculty of Nursing, Tanta University. Sample: Random sample of 60 undergraduate nursing students which are selected by using simple random method who are divided into; thirty students from second year and thirty students from fourth year. Tools: Four tools were used for data collection: Tool (I): Structure questionnaire sheet to assess student's knowledge regarding concept mapping, Tool (II): Case study rubric for assessing concept map, Tool (III): Problem solving skills assessment sheet and Tool (IV): Perception of students about using of concept map.

Results: As a result of this research, there were significant improvements among students knowledge about concept map, simulation case study rubric and problem solving skills, in addition to more than three quarter from students had positive perceptions regarding application of concept mapping in the clinical settings.

Conclusions and recommendation: Based on the findings of the study, there were significant improvement in the score of knowledge, simulation case study rubric and problem solving skills post application of concept mapping in the clinical setting. Therefore, it is necessary to improve wide-spreading of concept map training guidelines for large number of undergraduate nursing students at the level of the nursing faculties.
\end{abstract}

Key Words: Concept mapping, Teaching strategy, Competence and problem solving skills

\section{INTRODUCTION}

Clinical education is an essential part in the undergraduate nursing curriculum, the quality of nursing education depends on quality of the clinical experience, so undergraduate nursing students require effective clinical training to improve their competency in the application of theory in the clinical settings. ${ }^{[1]}$ Concept mapping is a powerful instructional tool that assists students to make connections between different nursing concepts. ${ }^{[2]}$ A concept mapping is a graphic organizer which uses schematic representation to hierarchically organize a set of concepts, connected by means of words in order to build meaningful statements. It shows meaning-

*Correspondence: Seham A. Abd El-Hay; Email: drsehamahmed@yahoo.com; Address: Faculty of Nursing, Tanta University, Tanta, Egypt. 
ful relationships between concepts and student's knowledge structure in the shape of map. ${ }^{[3]}$

Nowadays, nursing education aims not only to provide an appropriate level of knowledge and skills to undergraduate nursing students but also is expected to improve competency in problem solving skills and decision making abilities in different situations. ${ }^{[4]}$ So nursing students need for understanding of situations of their chosen field in the clinical settings and its relevant problems. A concept mapping provides a mean for students to consider all of the client's problems as a whole and then develops a plan to manage the problems, provides a mean not only to assess what is known about the client but also to determine what other information are needed, ${ }^{[5]}$ helps students to think more effectively as a group without losing their individuality, helps to manage the complexity of their ideas without losing detail and achieves various relations between main idea. ${ }^{[6]}$

Concept mapping is purposefully designed to work with groups and has a more structured process for organizing and visually representing the ideas of a group through a series of specific steps. ${ }^{[7]}$ Concept mapping consists of five steps: step one-develop a basic skeleton diagram that evolves from the clinical data where the students collect. Step twoanalyze and categorize data where students place clinical assessment data, history data and treatments under the appropriate nursing diagnosis. Step three-label and analyze nursing diagnoses relationships where students determine relationships among nursing diagnoses. Step four-identify goals, outcomes, and nursing interventions in the numbered order for each nursing diagnosis. Step five-evaluate client's responses where students evaluate, in writing, the client's responses. ${ }^{[5,8]}$

In Nursing, concept mapping is used to promote thinking, support problem solving, enable care planning, and evaluate nursing actions. ${ }^{[9,10]}$ Concept mapping is considered to be effective problem-solving tools that are improving the development of problem solving competency for undergraduate students. Problem solving is a complex activity which involves a variety of components that include knowledge, concepts and principles. ${ }^{[11,12]}$ Understanding problem solving process completely and correctly and using it for patient care is the basic condition of the development of the professional skills. ${ }^{[13]}$ So nursing students must be prepared to solve the health problems of clients, act in a professional and ethical manner when faced with complex situations. ${ }^{[14]}$

Developing a concept mapping is considered the foundation to solve a case study scenario during clinical training, enhance ability to provide comprehensive approach to solving a problem and improve competency in clinical settings. ${ }^{[15]}$
Competency of nursing students is an essential element for providing safe and quality of nursing practice. Therefore nursing students' needs broad-based preparations that include a wide scope of knowledge and skill from nursing and other related fields to meet the complex client needs. ${ }^{[16]}$ Concept mapping allows a student to develop ability to organize information in a meaningful way, allows nursing faculty to evaluate the undergraduate nursing student's understanding of the complex clients care needs, and promotes problem solving skills in the clinical setting. ${ }^{[17]}$ Therefore this study is to evaluate the effect of concept mapping on problem solving skills, competence in the clinical settings and knowledge among undergraduate nursing students.

\subsection{Significance of the study}

Nowadays nursing science becomes more advanced and complex, therefore nursing educators should apply new strategies in the clinical training that help undergraduate nursing student to learn more effectively. Educators have to employ the most recent teaching techniques, among which concept mapping that help students to understand concepts more deeply by designing their concept maps based on nursing process. ${ }^{[18]}$ Also help students to visualize of patient care priorities through a holistic view of the client that can be achieved through concept mapping more than nursing process and provide high cognitive function which promote problem solving skills. ${ }^{[19]}$ In addition to the minimal use of text or words makes it easy to scan for a word, phrase, or the general idea that is being explored. ${ }^{[9]}$

\subsection{Aim of the study}

The aim of this study was to evaluate the effect of concept mapping on problem solving skills, competence in the clinical settings and knowledge among undergraduate nursing students.

\section{SUBJECTS AND METHOD}

\subsection{Research hypothesis}

- Knowledge scores of undergraduate nursing students will exhibit to be improved after application of concept mapping in the clinical settings.

- Undergraduate nursing students were taught by using concept mapping in the clinical settings will exhibit to be improved in simulation case study rubric and problem solving skills.

\subsection{Research design}

A quasi-experimental design was used in the present research. 


\subsection{Setting}

The study was carried out at Medical \& Surgical Nursing Department and Community Health Nursing Department labs of the Faculty of Nursing, Tanta University, Departments and it's relevant Out Patient Clinics of Tanta University Hospital, T.B. Clinic and Seggar Maternal \& Child Health Centre affilated from Ministry of Health at Tanta City.

\subsection{Subjects}

Random sample of 60 undergraduate nursing students (one group from five groups for every mentioned departments) which are selected by using simple random method, each group was consisted of: thirty students from second year who were attending Medical and Surgical Nursing clinical course rotation during first term and thirty students from fourth year who were attending Community Health Nursing clinical course rotation during first term. Exclusion criteria are previous experience with concept mapping.

\subsection{Tools of data collections}

Four tools were used to collect the data for this study. These tools aimed to assess the effect of concept mapping on problem solving skills, competence in the clinical settings and knowledge among undergraduate nursing students.

Tool (I): Structure questionnaire sheet

It was comprised of two parts:

Part A: Socio-demographic characteristics of students which includes: students' code, age, sex, years, clinical setting area.

Part B: students' knowledge assessment sheet regarding concept mapping: It was developed by the researchers after reviewing of the related literatures ${ }^{[20-24]}$ to gather students' knowledge before and after implementation of concept mapping. It included the following: general knowledge about concept mapping as definition, importance, benefits, characteristics of concept mapping (12 questions), knowledge about building of concept map as steps and design of concept map (11 questions).

The scoring system of the knowledge: Two levels of scoring for questions were as follows:

- Correct answer scored (1)

- Don't know or incorrect answer scored (0)

The total scoring system of student's knowledge was 23, classified as follows:

- Good $>75 \%$ of the total score

- Fair $\geq 60 \%-75 \%$ of the total score

- Poor $<60 \%$ of the total score
Tool (II): Case study rubric for assessing concept map

Rubric for assessing case study of concept was developed by McMurray ${ }^{[25]}$ and Farrag et al. ${ }^{[26-29]}$ and modified by the researchers, it was used to evaluate the application of students' concept mapping in the clinical setting immediately, after two weeks and one month during follow up. It consisted of 6 statements that cover following points: arrangement of concept, links and linking line, hierarchical structure, content, depth of coverage and design.

The scoring system: It consisted of four point categorical score (4-1) that was offered for each statement, therefore (4) means excellent and (1) means unsatisfactory. The total scoring system was 24 , classified as follows:

- Satisfied concept map $75 \%$ of the total score

- Average concept map $\geq 60 \%-75 \%$ of the total score

- Unsatisfied concept map $<60 \%$ of the total score

Tool III: Problem solving skills assessment sheet

This tool was developed by the researchers based on current related literature. ${ }^{[30,31]}$ It consisted of a simulated case study that used immediately, after two weeks and one month during follows up to assess nursing students' ability to apply problem solving skills in formulating care plan following application of concept mapping. It consisted of questions based on real case study during clinical rotation in the clinical areas to assess nursing students' skills about how to cover knowledge regarding assessment, nursing diagnosis, planning, intervention and evaluation at the specific clinical area according to clinical rotation orders.

The scoring system was as follows:

- Done practice takes (1)

- Not done practice takes (0).

The total scoring system was calculated and classified as the following:

- Good $>75 \%$ of the total score.

- Fair $\geq 60 \%-75 \%$ of the total score.

- Poor $<60 \%$ of the total score.

Tool IV: Perception of students regarding application of concept map

The questionnaire was developed by the researchers after reviewing the related literature ${ }^{[32,33]}$ to elicit students' views about application of concept mapping in the clinical settings. Scoring system: Respondents were asked to indicate their level of agreement using a four points Likert type scale with fix values ranging from 1 to 4 , possible responses per item: (1) strongly disagrees, (2) disagree, (3) agree and (4) strongly agree. 


\subsection{Ethical consideration}

The necessary permission was obtained from the Faculty of Nursing Dean and head of the previous departments. Informed consent was taken from every nursing student to participate in the study and included the right to withdrawal at any time. Confidentiality was taken into consideration regarding data collection. A code number was used instead of names.

\subsection{Data collection}

The tools were tested for its content validity by a jury of five expertise in different fields of Medical \& Surgical and Community Health Nursing at Faculty of Nursing of Tanta University. Their opinions were elicited regarding tools format, consistency and scoring system, it was calculated and found to be $97 \%$. Reliability was calculated by cronbach, alpha test, it was found to be 0.883 .

A pilot study was conducted on $10 \%$ from study sample to test the feasibility and applicability of the tools and to determine any obstacles that may encountered during the period of data collection. They were excluded from the original sample.

Data collection for this study was carried out at the beginning of September 2017 to the December 2017.

Process of concept mapping: The concept mapping was conducted through four phases (assessment, planning, implementation and evaluation).

Assessment phase: The undergraduate nursing students were assessed in the 1st week before starting guidelines about concept mapping by using Tool (I) part A to collect baseline data and Tool I part B to assess knowledge related to concept mapping, to determine the duration and number of the sessions, the questionnaire sheet was filled by the students within 30 minutes.

Planning phase: The content of concept mapping guidelines were prepared by the researchers based on the related literature $^{[21,23,34-37]}$ and different teaching methods were used as lectures, brainstorming, class discussions, case studies, collaborative learning groups, and $\mathrm{CM}$ presentation, preparing equipment as paper and color pen to train them about design of concept map.

Concept mapping was conducted for each group according to specific clinical area in the time table of each departments as following: (4) sessions in two weeks for each group, about two days per week. Every group, take the same sessions in the same week according to their working days however, the time of each session will be about 1 hour.

Implementation phase: At the beginning of the study in the Published by Sciedu Press first week, first and second sessions were conducted before starting the application of concept mapping for each group according to time table in the clinical rotation for each department in the same week where First session includes: pretest for all nursing students and providing knowledge about concept mapping as: definition, the importance of $\mathrm{CM}$ in nursing education, benefits and characteristics. Second session includes: knowledge about steps that are needed to develop a $\mathrm{CM}$, steps of nursing process. In the second week third and fourth sessions were conducted for each group according to time table for each department where third session includes: relation between concept map and nursing process, training of students about how to design concept mapping based on the nursing process. Fourth session includes: using case scenario to inform students about how to apply of concept map for problem solving in the clinical settings.

The students in the course entitled Medical \& Surgical Nursing and Community Health Nursing were distributed on the clients in the clinical areas according to clinical rotation and time table of each department as following: for second year the first area immediately after application of concept mapping is orthopedic, during follow up after two weeks the second area is cardiology and third area is medical after one month to unify the case study and work of concept mapping for students. Concerning fourth year the first area immediately after application of concept map is TB clinic, during follow up after two weeks the second area is mobile clinic and third area is $\mathrm{MCH}$ after one month to unify the case study and work of concept mapping.

The students were worked individually in the clinical setting to collect the relevant data from the presented client to design concept mapping. They were started to collect data about client medical diagnosis or chief complaint, nursing diagnoses, subjective and objective data that are associated with the diagnosis, medical history, diagnostic tests, treatments, and medications, nursing intervention and evaluation for each nursing diagnosis.

After the students collected all data, they were started to design basic skeleton diagram of concept mapping by using an $11 \times 17$ sheet of paper with all collected data which includes: client medical diagnosis or chief complaint, then cluster data as clinical manifestations, diagnostic study, and medications related to nursing diagnosis. Link concepts and determine relationships by drawing an arrow among nursing diagnoses. After that the students identify goals, outcomes, and nursing interventions in the numbered order for each nursing diagnosis, at the end of work students evaluate the client's responses. ${ }^{[5,8]}$

At the end of each clinical area the researchers rounded, lis- 
tened to the students and observed the students' working to achieve level of understanding of how to assimilate the concept mapping and using in problem solving skills.

Evaluation phase: The nursing students were evaluated by using students' knowledge assessment sheet (Tool I) at pre and the end of the work. Case study rubric for assessing concept map (Tool II) was used immediately (during first area), follow up after two weeks (during second area) and after one month (during third area). Problem solving skills sheet (Tool III) was used immediately (during first area), follow up after two weeks (during second area) and after one month (during third area). And Perception of students about using of concept map in the clinical area (Tool IV) was used post implementation of concept mapping.

All data were collected, coded, tabulated and subjected to statistical analysis. Statistical analysis is performed by statistical Package SPSS in general (version 20), also Microsoft Office Excel is used for data handling and graphical presentation.

\section{Results}

Table 1 showed the distribution of the studied undergraduate nursing students according to their socio-demographic characteristics. As regard to age, the table was showed that the majority of students (93.3\%) with range from 19-22 years/old and only $6.7 \%$ were age from $18-19$ with mean age 20.07 \pm 1.12 . More than half $(58.3 \%)$ of them were female. As regard to academic years table were revealed that half of the students $(50 \%)$ from second year and another half from fourth year.

Figure 1 showed the level of undergraduate nursing students about general knowledge of concept mapping before and after application of concept mapping in the clinical setting. The figure was showed that there were significant improvement among nursing students regarding general knowledge about concept mapping (definition, importance, benefits and characteristics of concept mapping) before application of concept map from $73.3 \%$ poor, $16.7 \%$ fair and $10 \%$ good to $6.7 \%$ poor, $25 \%$ fair and $68.3 \%$ good after application of concept map.

Table 1. Distribution of socio-demographic characteristics of undergraduate nursing students

\begin{tabular}{|c|c|c|}
\hline \multirow{2}{*}{$\begin{array}{l}\text { Socio-demographic } \\
\text { Characteristics }\end{array}$} & \multicolumn{2}{|c|}{$\begin{array}{l}\text { Student sample } \\
(\mathrm{N}=60)\end{array}$} \\
\hline & $\mathbf{N}$ & $\%$ \\
\hline \multicolumn{3}{|l|}{ Age (year) } \\
\hline $18-<19$ & 4 & 6.7 \\
\hline $19-22$ & 56 & 93.3 \\
\hline Range & $18-22$ & \\
\hline Mean \pm SD & $20.07 \pm 1.12$ & \\
\hline \multicolumn{3}{|l|}{ Sex } \\
\hline Male & 25 & 41.7 \\
\hline Female & 35 & 58.3 \\
\hline \multicolumn{3}{|l|}{ Academic Years } \\
\hline Second & 30 & 50.0 \\
\hline Fourth & 30 & 50.0 \\
\hline \multicolumn{3}{|l|}{ Area of work } \\
\hline $\begin{array}{l}\text { Second year } \\
\text { First area: Orthopedic } \\
\text { Second area: Medical } \\
\text { Third area: Cardiology }\end{array}$ & 30 & 50.0 \\
\hline $\begin{array}{l}\text { Fourth year } \\
\text { First area: T.B. clinic } \\
\text { Second area: Mobile clinic } \\
\text { Third area: } \mathrm{MCH}\end{array}$ & 30 & 50.0 \\
\hline
\end{tabular}

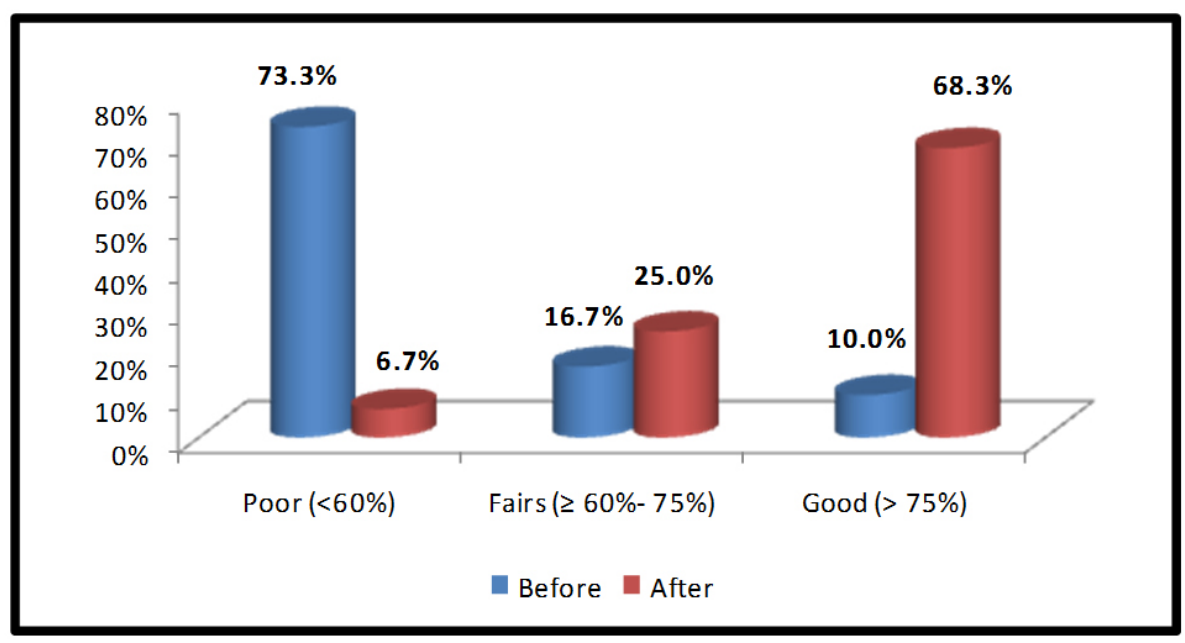

Figure 1. Level of undergraduate nursing students about general knowledge of concept map 
Figure 2 showed the level of undergraduate nursing student's about knowledge of building concept map before and after application of concept map in the clinical setting. The figure was showed that there were significant improvement among undergraduate nursing students regarding knowledge about building of concept mapping and its steps before application of concept map from $68.3 \%$ poor, $16.7 \%$ fair and $15 \%$ good to $6.7 \%$ poor, $25 \%$ fair and $68.3 \%$ good after application of concept mapping.

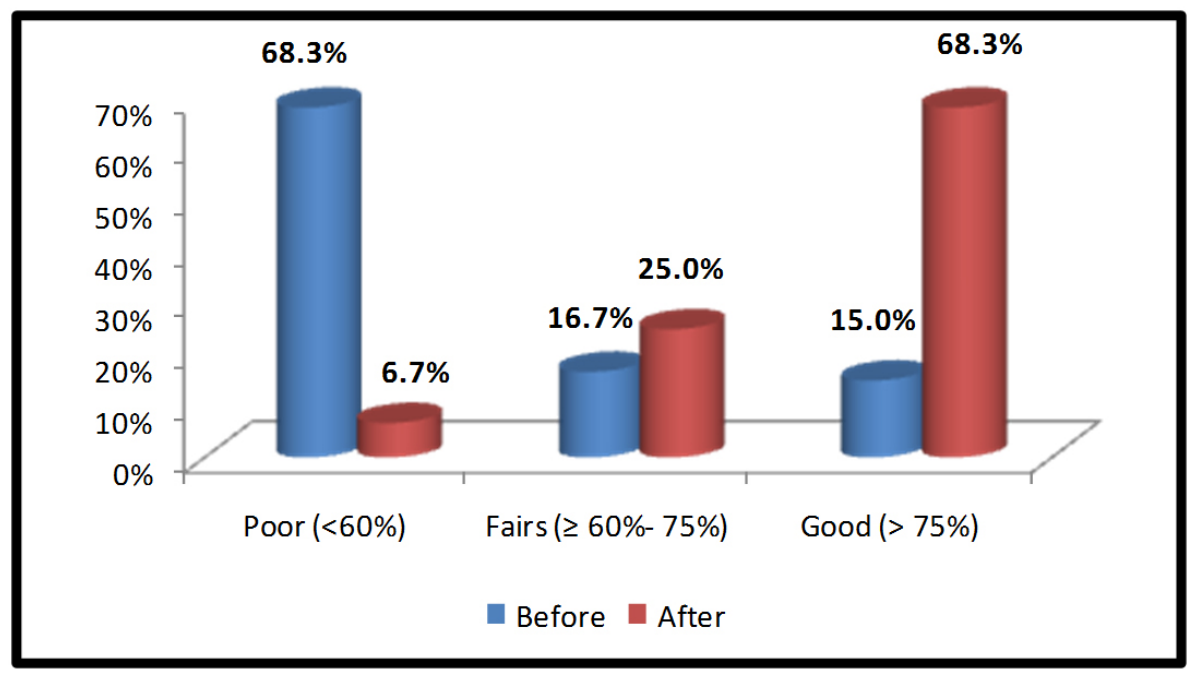

Figure 2. Level of undergraduate nursing student's about knowledge of building concept map

Table 2 showed the total level of students knowledge regard- tion of concept map from 65\% poor, 20\% fair and 15\% good ing concept map before and after application in the clinical to $6.7 \%$ poor, $13.3 \%$ fair and $80 \%$ good after application setting. Table 2 showed that there were significant improve- of concept map with statistical significant difference at $p=$ ment among nursing students total knowledge before applica- .001 .

Table 2. Total Level of undergraduate nursing student's knowledge regarding concept map

\begin{tabular}{|c|c|c|c|c|}
\hline \multirow{3}{*}{ Knowledge regarding concept map } & \multicolumn{4}{|c|}{ Student sample $(\mathrm{N}=60)$} \\
\hline & \multicolumn{2}{|c|}{ Before } & \multicolumn{2}{|c|}{ After } \\
\hline & No & $\%$ & No & $\%$ \\
\hline Poor $(<60 \%)$ & 39 & 65.0 & 6 & 6.7 \\
\hline Fairs $(\geq 60 \%-75 \%)$ & 12 & 20.0 & 8 & 13.3 \\
\hline Good (> 75\%) & 9 & 15.0 & 46 & 80.0 \\
\hline F & 23.75 & & & \\
\hline$p$ & $.001 *$ & & & \\
\hline
\end{tabular}

Table 3 showed the distribution of undergraduate nursing students regarding simulation case study rubric for assessing concept map. Table 3 showed that there were significant improvement in the students' simulation case study rubric (concept, links and linking line, hierarchical structure and use of example, content, depth coverage and design) immediately, after two weeks and after one month from application of concept mapping in the clinical settings with statistical significant difference at $p=.001 *, .000 *, .000 *, .003 *$ and $.012 *$ regarding concept, links and linking line, hierarchical structure and use of example, depth coverage and design respectively.

Table 4 showed the total level of students' simulation case study rubric for assessing concept map. The table was revealed that there were statistical significant improvement regarding simulation case study rubric for assessing concept map immediately, after two weeks and after one month from application of concept mapping in the clinical settings at $p=$ $.001 *$. 
Table 3. Distribution of undergraduate nursing students regarding simulation case study rubric for assessing concept map

\begin{tabular}{|c|c|c|c|c|c|c|c|}
\hline \multirow{2}{*}{ Performance indicators } & \multicolumn{2}{|c|}{ Immediately } & \multicolumn{2}{|c|}{ After two weeks } & \multicolumn{2}{|c|}{ After one month } & \multirow{2}{*}{$\begin{array}{l}\chi^{2} \\
p\end{array}$} \\
\hline & No & $\%$ & No & $\%$ & No & $\%$ & \\
\hline \multicolumn{8}{|l|}{ Concept } \\
\hline Unsatisfactory & 10 & 16.7 & 0 & 0.0 & 3 & 5.0 & \multirow{4}{*}{$\begin{array}{l}32.16 \\
.001 *\end{array}$} \\
\hline Satisfactory & 15 & 25.0 & 13 & 21.7 & 10 & 16.7 & \\
\hline Good & 24 & 40.0 & 29 & 48.3 & 23 & 38.3 & \\
\hline Excellent & 11 & 18.3 & 18 & 30.0 & 24 & 40.0 & \\
\hline \multicolumn{8}{|l|}{ Links and linking line } \\
\hline Unsatisfactory & 21 & 35.0 & 8 & 13.4 & 1 & 1.7 & \multirow{4}{*}{$\begin{array}{l}34.25 \\
.000 *\end{array}$} \\
\hline Satisfactory & 20 & 33.3 & 11 & 18.3 & 10 & 16.7 & \\
\hline Good & 14 & 23.3 & 30 & 50.0 & 29 & 48.3 & \\
\hline Excellent & 5 & 8.3 & 11 & 18.3 & 20 & 33.3 & \\
\hline \multicolumn{7}{|c|}{ Hierarchical structure with use of example } & \multirow{5}{*}{$\begin{array}{l}33.68 \\
.000 *\end{array}$} \\
\hline Unsatisfactory & 17 & 28.3 & 4 & 6.7 & 2 & 3.3 & \\
\hline Satisfactory & 24 & 40.0 & 10 & 16.7 & 8 & 13.3 & \\
\hline Good & 16 & 26.7 & 28 & 46.6 & 30 & 50.0 & \\
\hline Excellent & 3 & 5.0 & 18 & 30.0 & 20 & 37.3 & \\
\hline \multicolumn{8}{|l|}{ Content } \\
\hline Unsatisfactory & 15 & 25.0 & 0 & 0.0 & 0 & 0.0 & \multirow{4}{*}{$\begin{array}{l}30.29 \\
.022\end{array}$} \\
\hline Satisfactory & 23 & 38.3 & 10 & 16.7 & 5 & 8.3 & \\
\hline Good & 15 & 25.0 & 33 & 55.0 & 32 & 53.3 & \\
\hline Excellent & 7 & 11.7 & 17 & 28.3 & 23 & 38.3 & \\
\hline \multicolumn{8}{|l|}{ Depth coverage } \\
\hline Unsatisfactory & 19 & 31.7 & 8 & 13.4 & 5 & 8.3 & \multirow{4}{*}{$\begin{array}{l}29.46 \\
.003^{*}\end{array}$} \\
\hline Satisfactory & 21 & 35.0 & 22 & 36.7 & 13 & 21.7 & \\
\hline Good & 17 & 28.3 & 23 & 38.3 & 30 & 50.0 & \\
\hline Excellent & 3 & 5.0 & 7 & 11.7 & 12 & 20.0 & \\
\hline \multicolumn{8}{|l|}{ Design } \\
\hline Unsatisfactory & 17 & 28.3 & 9 & 15.0 & 0 & 0.0 & \multirow{4}{*}{$\begin{array}{l}39.42 \\
.012 *\end{array}$} \\
\hline Satisfactory & 26 & 43.3 & 12 & 20.0 & 6 & 10.0 & \\
\hline Good & 9 & 15.0 & 14 & 23.3 & 20 & 33.3 & \\
\hline Excellent & 8 & 13.4 & 25 & 41.7 & 34 & 56.7 & \\
\hline
\end{tabular}

Table 4. Total level of nursing students' regarding simulation case study rubric for assessing concept map

\begin{tabular}{|c|c|c|c|c|c|c|}
\hline \multirow{3}{*}{$\begin{array}{l}\text { Students' simulation case study Rubric } \\
\text { assessing concept map }\end{array}$} & \multicolumn{6}{|c|}{ Student sample $(\mathrm{n}=60)$} \\
\hline & \multicolumn{2}{|c|}{ Immediately after } & \multicolumn{2}{|c|}{ After two weeks } & \multicolumn{2}{|c|}{ After one month } \\
\hline & No & $\%$ & No & $\%$ & No & $\%$ \\
\hline Unsatisfied concept map $(<60 \%)$ & 35 & 58.3 & 6 & 10 & 2 & 3.3 \\
\hline Average concept map ( $\geq 60 \%-75 \%)$ & 21 & 35.0 & 20 & 33.3 & 17 & 28.4 \\
\hline Satisfied concept map (>75\%) & 4 & 6.7 & 34 & 56.7 & 41 & 68.3 \\
\hline $\mathrm{F}$ & 76.43 & & & & & \\
\hline$p$ & $.001^{*}$ & & & & & \\
\hline
\end{tabular}

Table 5 showed the level of students' competency for prob- concept mapping in the clinical settings as following: immelem solving skills in the clinical settings. Table 5 showed that diately $33.3 \%$ poor, $50 \%$ fair and $16.7 \%$ good to $11.7 \%$ poor, there were statistical significant improvement regarding stu- $28.3 \%$ fair and $60 \%$ good after two weeks and 3.3\% poor, dents' competency for problem solving skills immediately, $13.3 \%$ fair and $83.3 \%$ good after one month with $p=.000^{*}$. after two weeks and after one month from application of 
Table 5. Level of students' competency for problem solving skills in the clinical settings

\begin{tabular}{|c|c|c|c|c|c|c|}
\hline \multirow{3}{*}{ Problem solving skills } & \multicolumn{6}{|c|}{ Student sample $(n=60)$} \\
\hline & \multicolumn{2}{|c|}{ Immediately after } & \multicolumn{2}{|c|}{ After two weeks } & \multicolumn{2}{|c|}{ After one month } \\
\hline & No & $\%$ & No & $\%$ & No & $\%$ \\
\hline Poor $(<60 \%)$ & 20 & 33.3 & 7 & 11.7 & 2 & 3.3 \\
\hline Fairs ( $\geq 60 \%-75 \%)$ & 30 & 50 & 17 & 28.3 & 8 & 13.3 \\
\hline Good $(>75 \%)$ & 10 & 16.7 & 36 & 60.0 & 50 & 83.3 \\
\hline $\mathrm{F}$ & 50.64 & & & & & \\
\hline$p$ & $.000^{*}$ & & & & & \\
\hline
\end{tabular}

Table 6 showed the Correlation among knowledge, perception, simulation case study rubric for assessing concept map and problem solving skills. It was shown that there were statistical significant correlation among knowledge and perception, simulation case study rubric and problem solving skills at $p=.002 *, .021 *$ and $.003 *$ respectively. In addition, there were statistical significant correlation among perception and knowledge, simulation case study rubric and problem solving skills at $p=.0130 *, .014 *, .001 *$ respectively. And there were statistical significant correlations among simulation case study rubric and knowledge, perception and problem solving skills at $p=.002^{*}, .025^{*}, .001 *$ respectively. Also there were statistical significant correlation among problem solving skills and knowledge, perception and simulation case study rubric at $p=.023 *, .001 *, .024 *$ respectively.

Table 7 showed the perception of students regarding application of concept map in clinical setting. It was shown that about: $68.3 \%, 71.7 \%, 68.3 \%, 68.3 \%, 56.6 \%, 46.7 \%, 65.0 \%$, $56.7 \%, 55.0 \%, 63.4 \%, 71.7 \%$ and $55.0 \%$, from nursing stu- dents were agree that; concept map help to better understand nursing concepts, concept map help to improve critical thinking, using concept-map was useful for improving performance in clinical setting, concept map help to use knowledge in care of patients in clinical setting, concept map helps in better representation of case, concept map help to solve the problem better, concept map decrease work load when work with difficult case, learn to work with new learning method as concept map are different, concept map give opportunities to express opinions. Concept map help to know what I am good at, grades improved when work with Concept map, become friendly with my group members when use concept map respectively. While $65.0 \%, 43.3 \%, 73.2 \%, 46.7 \%$, and $43.3 \%$ from them were disagree about: using concept-mapping was useful for decreasing anxiety in clinical settings, concept map is an effective teaching/ learning/assessment tool, enjoy more when use concept map in clinical settings, concept map decrease consumed time that is needed to complete management and find concept map difficult to express thoughts and convert it to care for patient respectively.

Table 6. Correlation among knowledge, perception, simulation case study Rubric assessing and problem solving skills regarding concept map

\begin{tabular}{|c|c|c|c|c|}
\hline \multirow[t]{3}{*}{ Variables } & $\begin{array}{l}\text { Knowledge } \\
\text { regarding } \\
\text { concept map }\end{array}$ & $\begin{array}{l}\text { Perception regarding } \\
\text { application of concept } \\
\text { map in clinical setting }\end{array}$ & $\begin{array}{l}\text { Simulation case study } \\
\text { Rubric assessing } \\
\text { concept map }\end{array}$ & $\begin{array}{l}\text { Problem } \\
\text { solving } \\
\text { skills }\end{array}$ \\
\hline & $r$ & $r$ & $r$ & $r$ \\
\hline & $p$ & $p$ & $p$ & $p$ \\
\hline \multirow{2}{*}{ Knowledge regarding concept map } & \multirow{2}{*}{-} & 0.632 & 0.571 & 0.784 \\
\hline & & $.002 *$ & $.021 *$ & $.003^{*}$ \\
\hline \multirow{2}{*}{$\begin{array}{l}\text { Perception regarding application of } \\
\text { concept map in clinical setting }\end{array}$} & 0.643 & \multirow{2}{*}{-} & 0.741 & 0.730 \\
\hline & $.0130 *$ & & $.014^{*}$ & $.001^{*}$ \\
\hline \multirow{2}{*}{$\begin{array}{l}\text { Simulation case study Rubric assessing } \\
\text { concept map }\end{array}$} & 0.697 & 0.643 & \multirow{2}{*}{-} & 0.630 \\
\hline & $.002 *$ & $.025 *$ & & $.001^{*}$ \\
\hline \multirow{2}{*}{ Problem solving skills } & 0.842 & 0.710 & 0.633 & \multirow{2}{*}{-} \\
\hline & $.023^{*}$ & $.001^{*}$ & $.024^{*}$ & \\
\hline
\end{tabular}

$* p<.05, r=$ correlation coefficient. 
Figure 3 showed the total level of students' perception re- tive perceptions regarding application of concept mapping garding application of concept map in clinical setting. It in the clinical settings while $21.7 \%$ from them have negative was shown that $78.3 \%$ from total nursing students were posi- perception.

Table 7. Perception of undergraduate nursing students regarding application of concept map in clinical setting

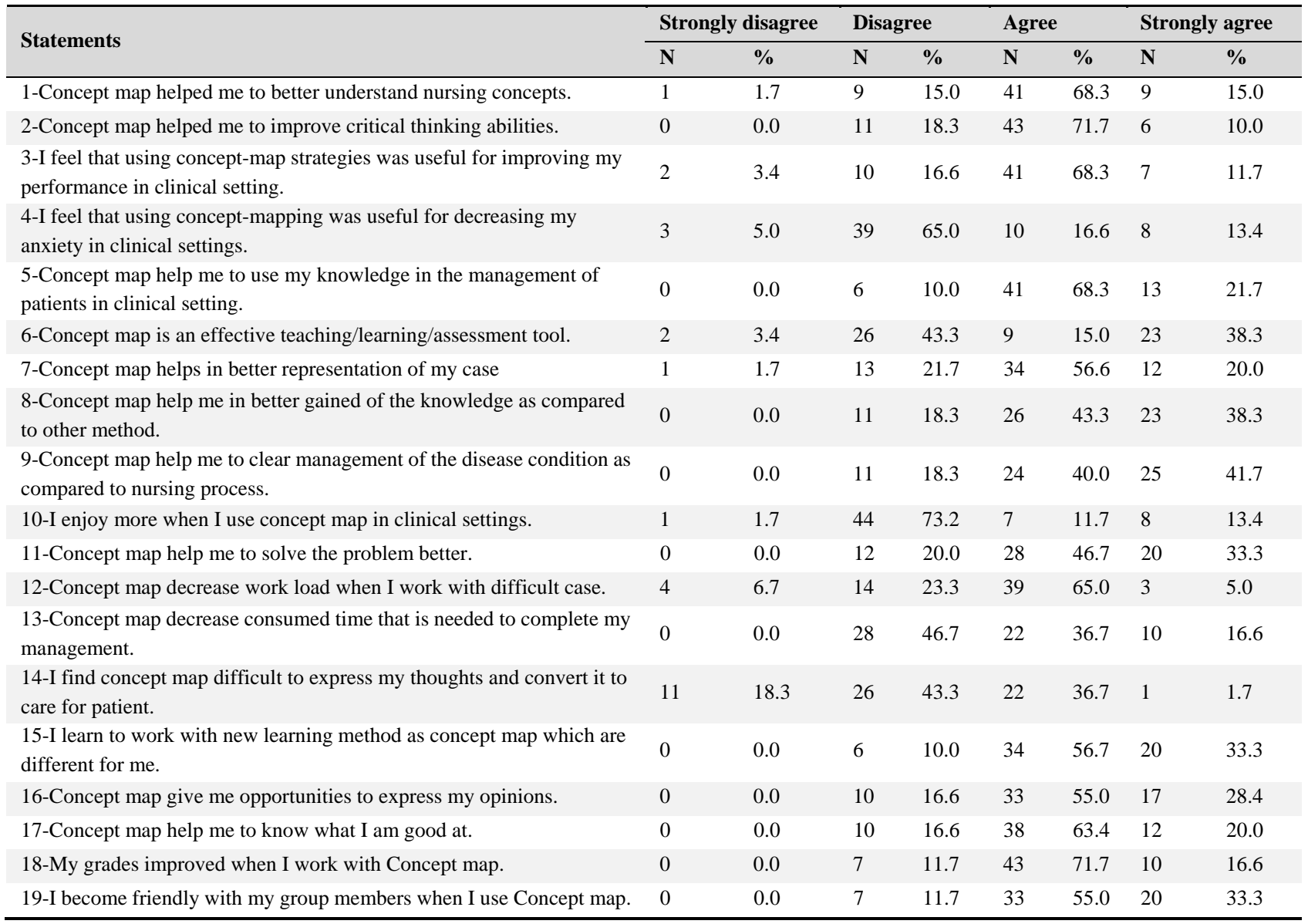

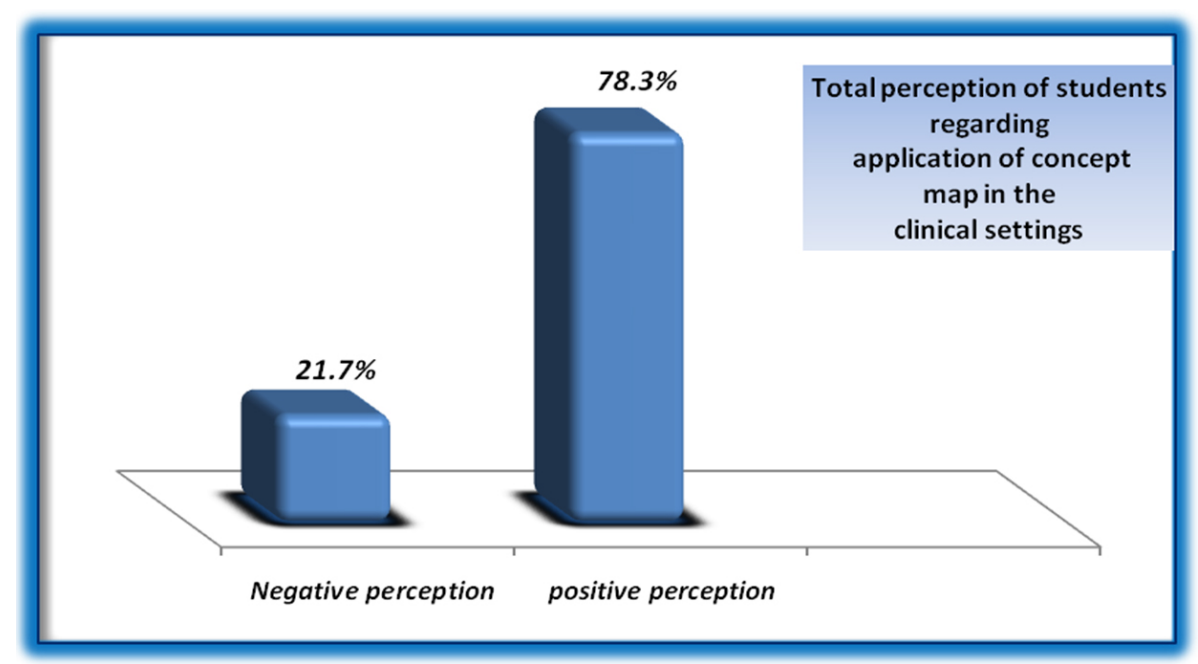

Figure 3. Level of students' perception regarding application of concept map in clinical setting 


\section{Discussion}

Concept mapping was originally created to provide a graphical representation of how to dissect and approach difficult ideas. ${ }^{[38]}$ Concept mapping can be an effective teachinglearning strategy that allows a student to develop the ability to organize information in a meaningful way, allows nursing faculty to evaluate the student's understanding of the complex patient care needs. ${ }^{[17]}$ This study aimed to evaluate the effect of concept mapping on problem solving skills, competence in the clinical settings and knowledge among undergraduate nursing students. In this respect Shern et al. (1995) ${ }^{[39]}$ said that according to their study, concept mapping can be used as a teaching approach in addition to problem-solving skills, and greater and longer cognition and quicker review.

Regarding to undergraduate nursing students' knowledge about concept mapping and its application in the clinical settings, the study results revealed that there were significant improvement among nursing students regarding general knowledge about concept mapping as (definition, importance, benefits and characteristics of concept mapping), knowledge about building concept map and its steps and total knowledge about concept map after application of concept map in the clinical settings. This may be due to the fact that concept mapping was helped students in structural knowledge on how to solve problems by searched for a solution and then implemented the care for the clients.

This result was in the line with Moahmed (2013) ${ }^{[40]}$ who reported that in her study, there were significant improvement in the nursing students' knowledge regarding concept mapping. Students were able to provide satisfactory knowledge about definition and uses of CM in nursing education and develop integrated $\mathrm{CM}$ at the end of the semester. On the other hand this finding were agreed with Eman (2014) ${ }^{[41]}$ who stated that there was a significant difference regarding knowledge about concept mapping among the study group from nursing students after awareness sessions regarding concept map. In addition to Edvane et al. $(2008)^{[42]}$ said that the use of guidelines for the construction of $\mathrm{CM}$ based to be important for the student to build diagrams containing data that generated diagnostics and nursing interventions, as well as to facilitate the correction of the diagrams based on the suggested scores.

As regard to level of undergraduate nursing students' regarding simulation case study rubric for assessing concept map after application in clinical settings. The study result showed that there were significant improvement in the nursing students' regarding simulation case study rubric (content, links and linking line, hierarchical structure with use of example, content, depth coverage and design) immediately, after two

Published by Sciedu Press weeks and after one month from application of concept map in the clinical settings. Also there were statistical significant improvement regarding total level of students regarding simulation case study rubric assessing concept map at $p=.001$. This finding were in the same line with Daley et al. $(2013)^{[43]}$ who stated that the score of the study group regarding the concept map rubric was improved from the first to the last assignment. Also Nirmala \& Shakuntala $(2011)^{[44]}$ said that in their study, the comparison of pretest and post test concept map rubric scores were showed significant difference in all the aspects of concept map except for the hierarchy.

In addition to Dosanjh (2011) ${ }^{[45]}$ who said that according to their study about effects of the concept mapping strategies on students' knowledge of the circulatory system as measured by rubric scores, the result showed that students in the studied group performed average on both the identification of the concepts (71\%) and the links (67\%). Additionally, students' posttest scores were correlated with their respective concept map scores. This result is in contrast with Farrag (2017) ${ }^{[46]}$ who stated that regarding the application of the rubric score to evaluate the students' concept map in his study group that more than half of the sample among study group had not achieved a satisfied score in the 1st assignment, less than half of the sample of the study group had average score, and no one achieved the satisfied concept map in the first trial.

As regard to undergraduate nursing students' competency for problem solving skills, the study results revealed that there were statistical significant improvement regarding students' competency for problem solving skills immediately, after two weeks and after one month from application of concept map in the clinical with $p=.000$. The finding is in the same line with Kamble \& Tembe (2013) ${ }^{[12]}$ who said that the result of their study showed that the students who was exposed to the use of concept mapping technique while studying was significantly higher in well structured problem solving than those students who exposed to traditional teaching method. In the same line Cheema \& Mirza (2013) ${ }^{[46]}$ \& Santiago (2011) ${ }^{[47]}$ who said that in their studies about concept maps as a learning tool have shown that concept mapping can increase academic success and improve students' problem-solving skills within a subject, primarily due to students being actively involved in their education.

Also the study result showed that there were statistical significant correlation among knowledge and perception, simulation case study rubric and problem solving skills, and among perception and knowledge, simulation case study rubric and problem solving skills and simulation case study rubric and knowledge, perception and problem solving. Also among problem solving skills and knowledge, perception and sim- 
ulation case study rubric. These finding is in the same line with BouJaoude \& Attieh (2008) ${ }^{[48]}$ who said that the result of their study showed that the total scores on the concept map showed a significant correlation with the scores on the application and level items on the posttest. In addition to Khrais $\&$ Saleh (2017) ${ }^{[49]}$ who said that by using concept map assessment rubric, a quasi-experimental study for 102 nursing students revealed that concept mapping is directly correlated with students' abilities to solve problem independently.

Regarding perceptions of students about application of concept map in clinical setting. The study results showed that most of the students agreed that: concept map helps in understand nursing concepts, helps to improve critical thinking, using concept-map was useful for improving performance in clinical setting, CM helps to use knowledge in the care of patients, CM helps in better representation of case, CM helps to solve problem, CM decreases work load, work with new learning method as concept map are different, CM gives opportunities to express opinions, grades improved when work with concept map, become friendly with group members after use it. While disagreed that; using concept-mapping was useful for decreasing anxiety in clinical settings, CM is effective teaching tool, enjoy when use concept map in clinical, CM decreases consumed time that is needed to complete management and find concept map difficult to express thoughts.

Also results showed that more than three quarter from students had positive perceptions regarding application of concept mapping in the clinical settings. The finding is in the same line with Black et al. $(2000)^{[50]}$ who said that concept map is shown to be effective in changing the students' attitude from being a passive to an active learner and also to promote their clinical practice. Also Moahmed (2013) ${ }^{[40]}$ stress that $\mathrm{CM}$ is suitable teaching strategy in many areas of learning. Students in the intervention group in this study reported a positive attitude toward using CM in clinical courses. In addition to Schuster (2000) ${ }^{[51]}$ said that in his study students commented that the concept map took a large amount of time, often more than 3 hours, to construct. Others also received feedback that concept mapping was time-consuming.

Also Nirmala \& Shakuntala $(2011)^{[43]}$ mentioned that the students felt that the concept map was very interesting and they motivated them to think out better. Few of the students found it difficult initially and able to draw the maps later. In addi-

\section{REFERENCES}

[1] Twentyman M, Eaton E. Enhancing Support for Nursing Students in the Clinical Setting. Nursing Times. 2006; 102(14): 35. tion to Buntting et al. $(2006)^{[52]}$ who said that in their study about $33 \%$ of the students also identified that concept mapping helped them to identify relationships between concepts. Also Senita (2008) ${ }^{[17]}$ said that in her research, a survey of nursing students at Kent State University, Ashtabula Campus, revealed that nursing students found concept mapping useful to their learning in the clinical setting and Wahl \& Thompson $(2013)^{[53]}$ said that in their research nursing students feeling satisfied and experiencing positive attitude toward clinical simulation and scenarios after utilizing concept maps in their clinical training.

\section{Conclusion}

In the light of the current study, it can be concluded that there were statistical significant improvements among undergraduate nursing students' knowledge about concept mapping after application in the clinical settings. Also there were significant improvement in the students' simulation case study rubric and problem solving skills immediately, after two weeks and after one month from application of concept map in the clinical settings. There were more than three quarter from students has positive perceptions regarding application of concept mapping in the clinical settings.

\section{Recommendation}

Based on results of the present study recommendation are suggested that:

- It is necessary to use concept mapping in the clinical setting as effective educational method to promote problem solving skills.

- Taking into consideration to use concept mapping as learning strategy in the clinical settings for larger number of students in the faculties.

- The nurse educators can be trained about how to use and teach concept mapping to plan the nursing care by the students in the clinical areas.

- It is necessary to develop of criteria for faculty members about how to assess and grade a concept map requires continued development.

- Further studies are needed to compare the effect of concept mapping with those of other metacognition approaches on different types of learners.

\section{Conflicts OF InTEREST Disclosure}

The authors declare that there is no conflict of interest.
[2] Markow PG, Lonning RA. Usefulness of Concept Maps in College Chemistry Laboratories: Students' Perceptions and Effects on Achievement. Journal of Research in Science Teaching. 1998; 35(9): 
1015-1029. https : //doi.org/10.1002/(SICI) 1098-2736(19 9811) 35: $9<1015:$ : AID-TEA4>3 . 0.CO;2-G

[3] Soares S, Teresa M. Using Concept Maps as A Strategy to Teach Physics in Particular the Topic of Acoustics, Concept Maps: Theory, Methodology, Technology proc. of the second int. Conference on Concept Mapping San José, Costa Rica. 2006.

[4] Kostovich C, Poradzisz M, Wood K. Learning Style Preference and Student Aptitude for Concept Maps. Journal of Nursing Education. 2007; 46(5): 225-231. PMid:17547346

[5] Timby BK, Smith NE. Introductory Medical-Surgical Nursing. 10th ed. Copyright by Wolters Kluwer Health. Lippincott Williams \& Wilkins. 2010.

[6] Lovitt TC, Horton SV. Strategies for Adapting Science Textbooks for Youth with Learning Disabilities. Remedial and Special Education. 1994; 15: 105-116. https://doi.org/10.1177/074193259401 500206

[7] Kane M, Trochim WM. Concept Mapping for Planning and Evaluation. Thousand Oaks, CA: Sage Publications; 2007.

[8] Schuster PM. Concept mapping: A Critical Thinking Approach to Care Planning. 2nd ed. Philadelphia, PA: F.A. Davis Company; 2008. $500 \mathrm{p}$.

[9] Lee W, Chiang CH, Liao IC, et al. The Longitudinal Effect of Concept Map Teaching on Critical Thinking of Nursing Students. Nurse Educ. Today. 2013; 33: 1219-23. PMid:22795871 https: //doi.org/10.1016/j.nedt.2012.06.010

[10] Tseng HC, Chou FH, Wang HH, et al. The Effectiveness of ProblemBased Learning and Concept Mapping among Taiwanese Registered Nursing Students. Nurse Educ. Today. 2011; 31(8): 41-46. PMid:21159411 https://doi.org/10.1016/j.nedt.2010.11 .020

[11] Stoyanov S, Kommers P. Intensive Concept Mapping for Metacognition in Solving Ill-Structured Problems. International Journal of Continuing Engineering Education and Lifelong Learning. 2006; 16(4): 297-316. https://doi .org/10.1504/IJCEELL . 2006.009205

[12] Kamble1 SK, Tembe BL. The Effect of Use of Concept Maps on Problem Solving Performance and Attitude in Mechanical Engineering Course, S.K. Procedia. Social and Behavioral Sciences. 2013; 83: 748-754. https://doi.org/10.1016/j.sbspro.2013.06.141

[13] Altun Q. The perceived Problem Solving Ability and Values of Student Nurses and Midwifes. Nurse Educ. Today. 2003; 23(8): 575-84. https://doi.org/10.1016/S0260-6917 (03)00096-0

[14] Masek A, Yamin S. The Effect of Problem Based Learning on Critical Thinking Ability: A Theoretical and Empirical Review. International Review of Social Sciences and Humanities. 2011; 2(1): 215-221.

[15] Popil I. Promotion of Critical Thinking by Using Case Studies as Teaching Method. Nurse Education Today. 2011; 31(2): 204-207. PMid:20655632 https://doi.org/10.1016/j.nedt.2010.06 .002

[16] Hird V. Nursing Competencies: The Artistry of Nursing. 2004.

[17] Senita J. The Use of Concept Maps to Evaluate Critical Thinking in the Clinical Setting. Teaching and Learning in Nursing. 2008; 3 : 6-10. https://doi.org/10.1016/j.teln.2007.08.002

[18] Hicks-Moore SL. Clinical Concept Maps in Nursing Education: An effective Way to Link Theory and Practice. Nurse Educ. Pract. 2005; 5(6): 348-52. PMid:19040844 https://doi.org/10.1016/j.ne pr.2005.05.003

[19] Aghakhani N, Sharif Nia H, Eghtedar S, et al. The Effect of Concept Mapping on the Learning Levels of Students in Taking the Course of Nursing Care of Patients With Glandular Diseases Subject in Urmia University of Medical Sciences, Iran. Jundishapur J. Chronic Dis Care. 2015; 4(2): 2838.

Published by Sciedu Press
[20] Hilten I. Concept Mapping 101. Available from: https://www.proprofs .com/quiz-school/story.php? title=concept - mapping $-101_{-} 1$

[21] Atay S, Karabacak U. Care Plans Using Concept Maps and their Effects on Critical Thinking Dispositions of Nursing Students. International Journal of Nursing Practice. 2012; 18: 233-239. PMid:22621292 https://doi .org/10.1111/j.1440-172X.20 $12.02034 . x$

[22] Billings D, Halstead J. Teaching in Nursing a Guide for Faculty. 3rd ed. St. Louis: Saunders Elsevier; 2009. 400 p.

[23] Schuster P. Concept Mapping: A Critical Approach to Care Planning 2nd ed. Philadelphia: FA Davis Company; 2011.

[24] Williams M. Concept Mapping: A Strategy for Assessment. Nursing Standard, Art and Science. 2008; 19 (9): 33-38.

[25] McMurray J. Rubric for assessing concept maps, University of Waterloo, California. 2014.

[26] Farrag RE. Concept Mapping Strategy: An Effective tool for Improving Maternity Nursing Students' Achievement. Journal of Nursing Education and Practice. 2017; 7(3): 12-13. http://dx. doi.org/1 $0.5430 /$ jnep.v7n3p10

[27] Written Case Presentation Student A. Sample Grand Canyon University. 2012; 1: 123.

[28] Gulanick M, Myers JL. Nursing Care Plans: Diagnoses, Interventions and Outcomes. 7th ed. St. Louis, MO: Mosby Com.; 2007. 123 p.

[29] Rubric for Assessing Concept Maps. Short URL: Adapted from Jennings educational development centr, Carleton university. 2012.

[30] Timby BK, Smith NE. Introductory Medical Surgical Nursing. 8th ed. London: Lippincott Williams \& Wilkins; 2003.

[31] Moyet LJC. Nursing Care Plans \& Documentation: Nursing Diagnosis and Collaborative Problems, 4th ed., New York: Lippincott Williams\& Wilkins; 2004. 900-1158 p.

[32] Duckworth AH. Cooperative Learning: Attitudes, Perceptions, and Achievement in a Traditional, Online, and Hybrid Instructional Setting, in Partial Fulfillment of the Requirements for the Degree of Doctor of Philosophy, University of Southern Mississippi; 2010.

[33] Howard VM. A Comparison of Educational Strategies for the Acquisition of Medical-Surgical Nursing Knowledge and Critical Thinking Skills: Human Patient Simulator vs. The interactive case Study Approach, Submitted to the Graduate Faculty of the School of Education in partial fulfillment of the requirements for the degree of Doctorate of Education, University of Pittsburgh; 2007.

[34] Billings D, Halstead J. Teaching in nursing a guide for faculty. 3rd ed. St. Louis: Saunders Elsevier; 2009.

[35] Ackley B, Ladwig G. Nursing Diagnosis Handbook an Evidence Based Guide to Planning Care (8th ed.). St. Louis: Mosby Elsevier; 2008. 322 p.

[36] Cyrst S, All A. Concept mapping: A road to Critical Thinking. Journal for Nurses in Staff Development. 2009; 25(2): 70-74. PMid:19346829 https://doi.org/10.1097/NND.0b013e3181 $9 \mathrm{e} 1082$

[37] Wilgis M, McConnell J. Concept Mapping: An Educational Strategy to Improve Graduate Nurses' Critical Thinking Skills during a Hospital Orientation Program. Journal of Continuing Education in Nursing. 2008; 39(3): 119-126. https://doi .org/10.3928/00220124-2 0080301-12

[38] Novak JD. Key Ideas Underlying Concept Maps and how they can be used. Cornell University and Institute for Human and Machine Cognition. 2002.

[39] Shern DL, Trochim WMK, LaComb CA. The Use of Concept Mapping for Assessing Fidelity of Model Transfer: An example from Psychiatric Rehabilitation. Eval. Program Plan. 1995; 18(2): 143-53. https://doi.org/10.1016/0149-7189(95)00005-V 
[40] Moahmed HF. Concept Mapping in Clinical Nursing: A Meaningful Learning. Life Science Journal. 2013; 10(12): 1037-1038.

[41] Salman ET. Concept Mapping as an Innovative Teaching Strategy to Enhance Cognitive Learning in Nursing Administration Course. International Journal for Innovation Education and Research. 2014; 2(7): 11-15.

[42] Edvane DD, Rosali O, Clara MM, et al. Concept Map Applied to the Development of Nursing Students' Clinical Judgment, Concept Mapping: Connecting Educators Proc. of the Third Int. Conference on Concept Mapping Tallinn, Estonia \& Helsinki, Finland. 2008. 3-4 p.

[43] Daley BJ, Shaw CR, Balistrieri T. Concept Maps: A Strategy to Teach and Evaluate Critical Thinking. Journal of Nursing Education. 2013; 38: 42-47.

[44] Nirmala T, Shakuntala BS. Concept Mapping - an Effective Tool to Promote Critical Thinking Skills among Nurses. Nujhs. 2011; 1(4) 2249-7110.

[45] Dosanjh N. The Effects of three Concept Mapping Strategies on Seventh-Grade Students' Science Achievement at an Urban Middle School, The Faculty of the School of Education, Learning and Instruction Department, In Partial Fulfillment of the Requirements for the Degree Doctor of Education. The University of San Francisco; May 2011. 12-24 p.

[46] Cheema AB, Mirza MS. Effect of Concept Mapping on Students' Academic Achievement. Journal of Research \& Reflections in Edu- cation. $2013 ; 7(2)$ : 125-132.

[47] Santiago HC. Visual Mapping to Enhance Learning and Critical Thinking Skills. Optometric Education. 2011; 36 (3): 125-139.

[48] BouJaoude S, Attieh M. the Effect of Using Concept Maps as Study Tools on Achievement in Chemistry. Eurasia Journal of Mathematics. Science and Technology Education. 2008; 4: 233-246. https://doi .org/10.12973/ejmste/75345

[49] Khrais H, Saleh A. The Outcomes of Integrating Concept Mapping in Nursing Education: An Integrative Review. Open Journal of Nursing. 2017; 7: 1335-1347. https://doi.org/10.4236/ojn.2017.7 11096

[50] Black P, Green N, Chapin BA, et al. Concept Mapping: an Alternative Teaching Strategy. Pelican News. 2000; 56(4): 6-10.

[51] Schuster PM. Concept mapping: Reducing clinical care plan paperwork and increasing learning. Nurse Educator. 2000; 25: 76-81. PMid:11052005

[52] Buntting C, Coll RK, Campbell A. Student Views of Concept Mapping Use in Introductory Tertiary Biology Classes. International Journal of Science and Mathematics Education. 2006; 4: 641-668. https://doi.org/10.1007/s10763-005-9014-7

[53] Wahl S, Thompson A. Concept Mapping in a Critical Care Orientation Program: A Pilot Study to Develop Critical Thinking and Decision Making Skills in Novice Nurses. The Journal of Continuing Education in Nursing. 2013; 44: 455-460. PMid:24053130 https ://doi.org/10.3928/00220124-20130916-79 